\title{
ATRIBUTOS DO SOLO SOB PASTAGENS EM SISTEMA DE SEQUEIRO E IRRIGADO
}

\section{Soil attributes under pasture system with and without irrigation}

\author{
Ana Lúcia Pereira ${ }^{1}$,Milton César Costa Campos $^{2}$, Zigomar Menezes de Souza ${ }^{3}$ Ítalo Heberte Lucena Cavalcante ${ }^{4}$, \\ Vagner Alves da Silva ${ }^{5}$, Marcílio Vieira Martins Filho ${ }^{6}$
}

\begin{abstract}
RESUMO
A pecuária é uma das atividades econômicas mais importantes da região do cerrado, sendo que o sucesso dessa atividade é dependente do sistema de manejo e de gramíneas forrageiras adaptadas às condições edafoclimáticas da região. Objetivou-se, neste tabalho, avaliar os atributos do solo em áreas sob pastagens com capim-Tanzânia (Panicum maximum Jacq. cv. Tanzânia) e braquiarão [Brachiaria brizantha (Hochst ex A. Rich.) Stapf. cv. Marandu], em sistema de sequeiro e irrigado no município de Rio Verde, GO. O experimento foi instalado no Centro Tecnológico Comigo, em um Latossolo Vermelho-Amarelo Distrófico típico, em 16 parcelas com $450 \mathrm{~m}^{2}$ cada. Adotou-se o delineamento em blocos completamente casualisados, referindo-se aos quatro tratamentos: capim-Tanzânia e braquiarão com e sem irrigação, com quatro repetições. Foram realizadas análises de atributos físicos (estabilidade de agregados) e químicas ( $\mathrm{pH}$, cálcio, magnésio, potássio, fósforo, acidez potencial, capacidade de troca catiônica, saturação por bases e conteúdo de matéria orgânica). Os atributos químicos variaram em ambas as profundidades, decorrentes principalmente da ação da calagem e adubação do solo independente da ausência ou presença de irrigação. Os tratamentos com capim-Tanzânia e braquiarão sem irrigação apresentaram os maiores teores de matéria orgânica e tiveram os maiores valores do diâmetro médio geométrico (DMG). A maior porcentagem dos agregados ficou retida na peneira de $>2,0 \mathrm{~mm}$ de malha. A irrigação não afetou a produção de massa seca do capimTanzânia e braquiarão.
\end{abstract}

Termos para Indexação: Gramíneas, capim-Tanzânia, capim-braquiarão, estabilidade de agregados, irrigação.

\begin{abstract}
The livestock production is one of the most important economic activities in the Brazilian savanna and its success depends on the management system used as well as the use of grasses adapted to the edaphoclimatic conditions of the region. Therefore, the aim of this work was to evaluate the soil attributes under pasture with Tanzania grass (Panicum maximum Jacq. cv. Tanzania) and bread grass [Brachiaria brizantha (Hochst ex A. Rich.) Stapf. cv. Marandu], with and without irrigation, in the municipality of Rio Verde, Goiás State, Brazil. The experiment was carried out on an oxisol soil at the Comigo Technological Center, in 16 plots of $450 \mathrm{~m}^{2}$ each. The experimental design used was the completely randomized blocks with four replications. The treatments consisted of two grass species, Tanzania grass (Panicum maximum) and bread grass (Brachiaria brizantha) and two irrigation treatments, with and without irrigation. The following attributes were determined: aggregate stability, $\mathrm{pH}$, calcium, magnesium, potassium, phosphorus, potential acidity, cation exchange capacity, base saturation, and organic matter content. The chemical attributes varied in both layers mainly due to the liming and fertilization of the soil, independently of the irrigation system. The treatments with Tanzania grass and bread grass without irrigation presented the highest organic matter content and the highest values of DMG. Most of the aggregates had a diameter larger than $2.0 \mathrm{~mm}$. The irrigation management did not affect the dry mass of the grasses studied.
\end{abstract}

Index terms: Pasture, Tanzania grass, bread grass, aggregate stability, irrigation.

(Recebido em 4 de setembro de 2007 e aprovado em 30 de julho de 2008)

\section{INTRODUÇÃO}

A região dos cerrados ocupa aproximadamente 20 $\%$ do território nacional e tem se apresentado como propícia para o aumento da fronteira agrícola brasileira, principalmente, devido às características físicas dos solos e à topografia favorável ao cultivo intensivo. No entanto, os solos dessa região apresentam rápida mineralização da

\footnotetext{
'Engenheira Agrônoma, Doutora em Irrigação e Drenagem - Departamento de Pesquisa Agropecuária,Campo Experimental de Rio Verde - Agência Goiânia de Desenvolvimento Rural e Fundiário/AGENCIARURAL - 75901-210 - Rio Verde, GO - pesquisa1@agenciarural.go.gov.br

${ }^{2}$ Engenheiro Agrônomo, Doutorando em Ciência do Solo - Departamento Colegiado do Curso de Engenharia Ambiental - Instituto de Agricultura e Ambiente/Universidade Federal do Amazonas/UFAM - 69800-000 - Humaitá, AM - agromccc@yahoo.com.br

${ }^{3}$ Engenheiro Agrônomo, Doutor em Produção Vegetal - Departamento de Água e Solo - Universidade de Campinas/UNICAMP - Cx. P. 6011 - $13083-875$ Campinas, SP - zigomarms@agr.unicamp.br

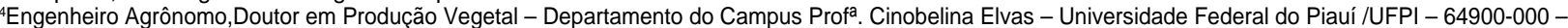
Bom Jesus, PI - italounesp@yahoo.com.br

${ }^{5}$ Engenheiro Agrônomo, Mestre em Produção Vegetal - Departamento de Pesquisa Agropecuária,Campo Experimental de Rio Verde - Agência Goiânia de Desenvolvimento Rural e Fundiário/ AGENCIARUAL - 75901-210 - Rio Verde, GO - vasilva@yahoo.com.br

${ }^{6}$ Engenheiro Agrônomo,Doutor em Solos e Nutrição de Plantas - Departamento de Solos e Adubos - Faculdade de Ciências Agrarias e Veterinária,Universidade Estadual Paulista/UNESP - 14884-900 - Jaboticabal, SP - mfilho@fcav.unesp.br
} 
matéria orgânica, devido às elevadas temperaturas e umidade do solo, durante boa parte do ano (MENDES et al., 2003). Essa característica dificulta a adequada reposição de nutrientes nos sistemas convencionais de manejo dos solos e das culturas (KLUTHCOUSKI et al., 2000).

Os solos de Cerrado, em geral, apresentam características químicas desfavoráveis, são ácidos, com reduzida disponibilidade de nutrientes, alta saturação por alumínio e elevada capacidade de adsorção de fósforo. Assim, para o sucesso da exploração agropecuária, é necessária a adoção de técnicas apropriadas, como uso de corretivos e fertilizantes e/ou a introdução de espécies vegetais adaptadas às condições edafoclimáticas (FAQUIN et al., 2000).

Do ponto de vista pedogenético e químico, os solos sob vegetação de cerrado são altamente intemperizados, isto é, passaram por processos geologicamente longos, cerca de 100 milhões de anos em que houve intensa lixiviação de bases e redução dos teores de sílica. O material residual corresponde, na fração argila, a óxidos de ferro e alumínio e, geralmente argilominerais como a caulinita. Dados de Lopes \& Guilherme (1992) indicaram que os teores de cálcio apresentaram amplitude de variação entre 0,04 e $6,8 \mathrm{cmol}_{\mathrm{c}} \mathrm{kg}^{-1}$, com cerca de $96 \%$ dos solos abaixo de $1,5 \mathrm{cmol}_{\mathrm{c}} \mathrm{kg}^{-1}, \mathrm{e} 74 \%$ abaixo de $0,4 \mathrm{cmol}_{\mathrm{c}} \mathrm{kg}^{-1}$. Por outro lado, a alta saturação por alumínio é sinônimo de baixa saturação por bases. A deficiência de cálcio e magnésio, muitas vezes associada ao excesso relativo de alumínio nas camadas subsuperficiais do solo, reduz o desenvolvimento do sistema radicular, tornando as plantas mais suscetíveis à seca (veranicos). Os teores de matéria orgânica na maioria dos solos sob vegetação de cerrado, para a camada superficial, situam-se entre 2 e $3 \%$, o que resulta em baixos conteúdos de nitrogênio, enxofre e boro potencialmente mineralizáveis (LONGO et al., 1999).

De acordo com Soares et al. (2000) estima-se que, dos 48 milhões de hectares cultivados com pastagens existentes na região, mais da metade sejam ocupados com Brachiaria decumbens. No estado de Góias, os Latossolos são cultivados com gramíneas do gênero Brachiaria e, dentre elas, pode-se destacar o braquiarão, uma das espécies mais cultivadas. Segundo Carvalho et al. (1984) essas braquiárias são espécies de menor exigência nutricional e são tolerantes à acidez do solo.

Outra cultivar de destaque na região é o capimTanzânia (Panicum maximum Jacq. cv. Tanzânia), originado da África. Possui boa altura média, boa produção de massa verde e protege bem o solo, quando adubado e manejado de forma adequada. De acordo com Euclides (1994) a cultivar Tanzânia, em solo fértil, promove maior ganho de peso animal, quando comparada a cultivares do gênero
Panicum, o que está de acordo com a maior exigência dessa planta e sua alta resposta à adubação com fósforo.

$\mathrm{O}$ cultivo intensivo e o sistema de manejo interferem nos atributos físicos, químicos e biológicos do solo, promovendo alterações desses atributos e influenciando na capacidade produtiva do solo. Entre eles, destaca-se a agregação do solo. Por isso, a estabilidade de agregados tem sido usada como indicador da qualidade física do solo, pois é sensível às alterações, conforme o manejo adotado. O tipo de vegetação também interfere na estruturação dos solos, ou seja, as gramíneas são mais eficientes em aumentar e manter a estabilidade de agregados do que as leguminosas (CARPENEDO \& MIELNICZUK, 1990), por apresentarem um sistema radicular extenso e renovado constantemente.

Aproximadamente $80 \%$ das pastagens da região do cerrado encontram-se em algum grau de degradação, com baixa produtividade e capacidade de suporte (LIMA et al., 2000). Entre outras razões, a baixa produtividade é explicada pela não aplicação de fertilizantes e corretivos nas quantidades recomendadas e pela degradação da qualidade física do solo. Objetivou-se, neste trabalho, avaliar os atributos do solo em áreas sob cultivo de pastagem com capim-Tanzânia e braquiarão, em sistema de sequeiro e irrigado no município de Rio Verde, GO.

\section{MATERIAL E MÉTODOS}

A área de estudo está localizada no Sudeste do estado de Goiás, no município de Rio Verde, com coordenadas geográficas: $17^{\circ} 47^{\prime}$ de latitude sul e $51^{\circ} 55^{\prime}$ de longitude oeste, com altitude média de $768 \mathrm{~m}$ acima do nível do mar. O clima da região é do tipo Aw, definido como tropical úmido com estação chuvosa no verão e seca no inverno, segundo a classificação de Köppen. A temperatura média anual varia entre 20 e $35^{\circ} \mathrm{C}$ e as precipitações oscilam entre $1.500 \mathrm{a} 1.800 \mathrm{~mm}$ anuais. O solo da área em estudo foi classificado como Latossolo Vermelho-Amarelo Distrófico típico (LVd), segundo Embrapa (2006). A vegetação original encontrada na área foi descrita como sendo do tipo cerrado.

O preparo do solo foi realizado por meio de uma gradagem aradora e duas gradagens niveladoras. Durante o preparo foi efetuada a correção do solo, com a aplicação de calcário a lanço para elevar a saturação de bases a $80 \%$. O experimento foi instalado no ano de 2000, em área do Centro Tecnológico Comigo, em solo recém-preparado e anteriormente cultivado com gramíneas do gênero Brachiaria, por 6 anos sob pastejo. Foram utilizadas 16 parcelas (piquetes) com $450 \mathrm{~m}^{2}$ cada, todas as parcelas apresentavam o mesmo número de unidade animal. A lotação animal foi ajustada conforme a produção de massa 
forragem avaliada a cada ciclo de pastejo. O delineamento experimental foi o de blocos completos ao acaso, com quatro tratamentos e quatro repetições.

A semeadura foi realizada adicionando-se $9 \mathrm{~kg}$ de sementes puras viáveis ao adubo de plantio $\left(550 \mathrm{~kg} \mathrm{ha}^{-1}\right.$ da fórmula comercial 5-25-20 + Zn). A adubação foi realizada a lanço, com a mesma quantidade em todas as parcelas. Após 15 dias da emergência das plantas, foi realizada uma adubação de cobertura com $80 \mathrm{~kg} \mathrm{ha}^{-1}$ de uréia. Para a irrigação, utilizou-se o sistema de aspersão convencional, aplicando-se uma lâmina de água diária de $9 \mathrm{~mm}$ quando necessário. $\mathrm{O}$ manejo da irrigação foi realizado tomando como referência o potencial de água no solo, cujo monitoramento foi por tensiômetros.

Após um ano de instalação do experimento foram coletadas, com um trado, 5 amostras compostas de solo (3 subamostras) nas profundidades de 0,0-0,1 m e 0,1-0,2 m, para análise dos atributos químicos do solo. Os teores de cálcio, magnésio e potássio trocáveis e fósforo disponível foram extraídos utilizando-se o método da resina trocadora de íons (RAIJ et al., 2001). A acidez trocável $\left(\mathrm{Al}^{3+}\right)$ e acidez potencial $\left(\mathrm{H}^{+}+\mathrm{Al}^{3+}\right)$ foram determinadas seguindo a metodologia de Raij \& Zullo (1977) e o pH determinado potenciometricamente, utilizando-se relação 1:2,5 de solo, em $\mathrm{CaCl}_{2}$. A capacidade de troca de cátions (CTC) efetiva foi estimada pela soma dos teores de $\mathrm{Ca}, \mathrm{Mg}, \mathrm{K}$ e $\mathrm{Al}$ trocáveis. A matéria orgânica foi determinada para a profundidade do solo de 0,0-0,2m, segundo metodologia da Embrapa (1997).

Para a determinação dos agregados, foram abertas 5 trincheiras por parcela, para coleta das amostras de solos com enxadão, na profundidade de $0,0-0,2 \mathrm{~m}$. As amostras de solo foram levemente destorroadas, de forma manual, passadas em peneira de 7,93mm de diâmetro de malha e seca à sombra. A separação e estabilidade de agregados foram determinadas segundo Kemper \& Chepil (1965), com modificações, nas seguintes classes de diâmetro: >2,0; 2,0-1,0; 1,0-0,50; 0,500,$25 ; 0,25-0,105 \mathrm{~mm}$. Os agregados foram colocados em contato com a água sobre a peneira de $4,76 \mathrm{~mm}$ por quinze minutos e a massa do material retido em cada peneira foi colocada em estufa a $105^{\circ} \mathrm{C}$. Os resultados foram expressos em porcentual de agregados retidos nas peneiras $>2,0 \mathrm{~mm}, 2,0-1,0 \mathrm{~mm}$ e $<1,0 \mathrm{~mm}$ e diâmetro médio geométrico (DMG).

Para a avaliação da matéria seca da massa de forragem, foi utilizada uma moldura de $2 \mathrm{~m}$ x $2 \mathrm{~m}$, que foi jogada, aleatoriamente, quatro vezes na parcela. A forrageira foi cortada rente ao solo, e a massa coletada foi pesada no campo, para determinar-se a massa fresca. Desse material fresco, foram retiradas amostras (aproximadamente $0,4 \mathrm{~kg}$ ), para secagem em estufa a $105 \mathrm{C}$, por 24 horas, obtendo-se a matéria seca. As coletas foram realizadas na estação das "águas" no verão, um ano após a implantação do experimento, distribuídas em dois períodos, com intervalos de 40 dias entre o primeiro e o segundo corte.

Os dados foram submetidos à análise de variância utilizando-se o programa estatístico SAS e as médias comparadas pelo teste de Tukey, a 5\% de probabilidade.

\section{RESULTADOS E DISCUSSÃO}

A composição granulométrica dos solos estudados é apresentada na Tabela 1 .

Os atributos químicos $\mathrm{K}, \mathrm{P}$ e CTC nas profundidades estudadas e $\mathrm{H}+\mathrm{Al}$ na profundidade $0,1-0,2$ $\mathrm{m}$ foram afetados pelos cultivos de pastagem com e sem irrigação, cujos valores encontram-se na Tabela 2 . Observaram-se os maiores teores de $\mathrm{P}$ disponível no solo, nos tratamentos de cultivo com capim braquiarão com e sem irrigação, na profundidade de 0,0-0,1 m (13,14 e 9,96 $\mathrm{mg} \mathrm{dm}{ }^{-3}$, respectivamente).

Tabela 1 - Análise granulométrica de amostras do horizonte superficial do Latossolo Vermelho-Amarelo Distrófico típico, sob diferentes condições de manejo no município de Rio Verde, GO.

\begin{tabular}{|c|c|c|c|c|}
\hline \multirow{3}{*}{ Sistemas de Manejo } & \multirow[t]{2}{*}{ Profundidade } & \multicolumn{3}{|c|}{ Composição Granulométrica } \\
\hline & & Areia & Silte & Argila \\
\hline & $\mathrm{m}$ & \multicolumn{3}{|c|}{---------------------------- g kg ${ }^{-1}----------------------$} \\
\hline \multirow[t]{2}{*}{ Tanzânia Irrigado } & $0,0-0,1$ & 581,2 & 60,3 & 358,5 \\
\hline & $0,1-0,2$ & 522,8 & 60,6 & 416,6 \\
\hline \multirow[t]{2}{*}{ Tanzânia Sequeiro } & $0,0-0,1$ & 522,8 & 60,6 & 416,6 \\
\hline & $0,1-0,2$ & 522,8 & 60,6 & 416,6 \\
\hline \multirow[t]{2}{*}{ Braquiarão Irrigado } & $0,0-0,1$ & 556,0 & 60,6 & 383,4 \\
\hline & $0,1-0,2$ & 522,8 & 60,6 & 416,6 \\
\hline \multirow[t]{2}{*}{ Braquiarão Sequeiro } & $0,0-0,1$ & 489,6 & 93,8 & 416,6 \\
\hline & $0,1-0,2$ & 489,0 & 60,0 & 451,0 \\
\hline
\end{tabular}


Tabela 2 - Teores médios de $\mathrm{pH}$, cálcio, magnésio, potássio, fósforo, acidez potencial, capacidade de troca catiônica e saturação de bases do solo, cultivadas com pastagem irrigada e de sequeiro.

\begin{tabular}{|c|c|c|c|c|c|c|c|c|}
\hline \multirow{2}{*}{$\begin{array}{c}\text { Sistema de } \\
\text { Manejo }\end{array}$} & $\mathrm{pH}$ & $\mathrm{Ca}$ & $\mathrm{Mg}$ & $\mathrm{K}$ & $\mathrm{H}+\mathrm{Al}$ & $\mathrm{P}$ & CTC & $\mathrm{V} \%$ \\
\hline & $\mathrm{CaCl}_{2}$ & \multicolumn{4}{|c|}{ - } & $\mathrm{mg} \mathrm{dm}^{-3}$ & $\mathrm{mmol}_{\mathrm{c}} \mathrm{dm}^{-3}$ & \\
\hline \multicolumn{9}{|c|}{ Profundidade $(0,0-0,1 \mathrm{~m})$} \\
\hline $\begin{array}{l}\text { Tanzânia } \\
\text { Irrigado }\end{array}$ & $5,15 \mathrm{a}$ & $28,00 \mathrm{a}$ & $9,00 \mathrm{a}$ & $3,50 \mathrm{a}$ & 27,7 a & $7,31 \mathrm{~b}$ & $66,6 \mathrm{~b}$ & 58 a \\
\hline $\begin{array}{l}\text { Tanzânia } \\
\text { Sequeiro }\end{array}$ & $5,13 \mathrm{a}$ & $31,00 \mathrm{a}$ & $8,80 \mathrm{a}$ & $3,30 \mathrm{a}$ & $32,5 \mathrm{a}$ & $7,69 \mathrm{~b}$ & $74,8 \mathrm{ab}$ & 57 a \\
\hline $\begin{array}{l}\text { Braquiarão } \\
\text { Irrigado }\end{array}$ & $5,18 \mathrm{a}$ & 29,50 a & $8,70 \mathrm{a}$ & $1,70 \mathrm{a}$ & $28,5 \mathrm{a}$ & 10,96 a & $68,2 \mathrm{ab}$ & $58 \mathrm{a}$ \\
\hline $\begin{array}{l}\text { Braquiarão } \\
\text { Sequeiro }\end{array}$ & 5,18 a & 34,60 a & $9,00 \mathrm{a}$ & $5,60 \mathrm{a}$ & $31,0 \mathrm{a}$ & $13,14 \mathrm{a}$ & $80,2 \mathrm{a}$ & $61 \mathrm{a}$ \\
\hline $\mathrm{CV}(\%)$ & 7,31 & 31,11 & 30,42 & 29,61 & 20,04 & 38,11 & 15,41 & 20,10 \\
\hline \multicolumn{9}{|c|}{ Profundidade $(0,1-0,2 \mathrm{~m})$} \\
\hline $\begin{array}{l}\text { Tanzânia } \\
\text { Irrigado }\end{array}$ & $4,70 \mathrm{a}$ & $16,8 \mathrm{a}$ & $0,30 \mathrm{a}$ & $0,70 \mathrm{~b}$ & $40,7 \mathrm{ab}$ & $2,16 \mathrm{~b}$ & $61,3 \mathrm{a}$ & $33 \mathrm{a}$ \\
\hline $\begin{array}{l}\text { Tanzânia } \\
\text { Sequeiro }\end{array}$ & $4,55 \mathrm{a}$ & 17,6 a & $0,42 \mathrm{a}$ & $0,60 \mathrm{~b}$ & $49,2 \mathrm{a}$ & $2,16 \mathrm{~b}$ & $71,8 \mathrm{a}$ & $31 \mathrm{a}$ \\
\hline $\begin{array}{l}\text { Braquiarão } \\
\text { Irrigado }\end{array}$ & $4,80 \mathrm{a}$ & $15,0 \mathrm{a}$ & $0,43 \mathrm{a}$ & $0,90 \mathrm{ab}$ & $33,2 \mathrm{~b}$ & $1,82 \mathrm{~b}$ & 53,6 a & 38 a \\
\hline $\begin{array}{l}\text { Braquiarão } \\
\text { Sequeiro }\end{array}$ & $4,63 \mathrm{a}$ & 19,9 a & $0,38 \mathrm{a}$ & $1,40 \mathrm{a}$ & $47,2 \mathrm{ab}$ & $6,93 \mathrm{a}$ & $72,5 \mathrm{a}$ & $35,18 \mathrm{a}$ \\
\hline CV (\%) & 5,47 & 27,06 & 28,17 & 27,05 & 17,82 & 36,17 & 13,12 & 18,08 \\
\hline
\end{tabular}

Médias seguidas de mesmas letras, nas colunas, não diferem entre si pelo teste de Tukey, ao nível de $5 \%$ de probabilidade entre os sistemas de manejo e profundidade.

Na profundidade de $0,1-0,2 \mathrm{~m}$, as concentrações de fósforo foram menores (Tabela 2). O acúmulo de P na superfície é justificado pela baixa mobilidade desse nutriente no solo e pela adubação a lanço, em superfície. Os teores médios de fósforo nas duas profundidades estudadas foram considerados de baixo a muito baixos, de acordo com a recomendação da Comissão de Fertilidade do Solo de Goiás - CFSG (1988). Em vários trabalhos relatados pela CIAT (1988), as braquiárias foram consideradas capazes de se desenvolver em solos com baixos teores de $\mathrm{P}$ disponível, pois possuem alta capacidade de extração, não necessitando mais do que 45 $\mathrm{kg} \mathrm{P}_{2} \mathrm{O}_{5}$ ha $^{-1}$, já o capim-Tanzânia é mais exigente em $\mathrm{P}$ (PINHEIRO, 2002). Segundo Boddey et al. (1996), o P é um dos nutrientes mais importantes na formação, renovação e manutenção de pastagens, em solos tropicais.

Os teores de cálcio e magnésio trocáveis não foram afetados pelos sistemas cultivos de pastagem, nas profundidades estudadas, embora os valores tenham sido maiores na profundidade de $0,0-0,1 \mathrm{~m}$ (Tabela 2), fato que, provavelmente, esteja relacionado à adição de calcário na superfície, reciclagem do $\mathrm{Ca}$ e $\mathrm{Mg}$ via decomposição de resíduos e aumento da CTC do solo, capaz de reter mais cátions nessa profundidade (BAYER \& MIELNICZUK, 1997).

Embora as forrageiras em estudo sejam consideradas tolerantes à toxidez por alumínio, o efeito do calcário nessas gramíneas, não atua somente como corretivo da acidez, mas como fonte de cálcio e magnésio, o que melhora a qualidade da pastagem, do ponto de vista nutricional (KLIEMANN et al., 2003). Porém, Lima et al. (2000), estudando a aplicação de macro e micronutrientes em áreas de cerrado cultivadas com pastagem, afirmaram que há necessidade de aplicação do Ca e $\mathrm{Mg}$ como nutriente e, não só via calagem. Nascimento et al. (2002) não verificaram efeito da calagem sobre a produção de matéria seca do capim-Tanzânia, na região do cerrado. 
O tratamento braquiarão de sequeiro apresentou os maiores teores de $\mathrm{K}$ quando comparado aos demais tratamentos, entretanto a saturação em potássio está dentro da faixa recomendável em todos os tratamentos estudados (Tabela 2). Segundo Souza (1993) os valores de $\mathrm{K}$ para todos os tratamentos são considerados baixos para a região do cerrado, porém, a relação entre o teor de K e a CTC (saturação em potássio) deve estar dentro da faixa de 3 a $5 \%$, para as culturas mais exigentes.

Em relação ao pH, os tratamentos com Tanzânia e braquiarão apresentaram diferenças significativas para as profundidades estudadas (Tabela 2), corroborando com o observado por Cruz et al. (1994). Segundo Souza (1993) para os solos sob vegetação de cerrado, os valores de $\mathrm{pH}$ correspondem a nível de acidez média na profundidade de $0,0-0,1 \mathrm{~m}$ e maior acidez na profundidade de 0,1-0,2 m. Os valores menos ácidos na camada superficial provavelmente devem-se à aplicação do calcário a lanço sem incorporação. Segundo Carvalho et al. (1992), a aplicação de calcário, elevando o pH do solo traz outros benefícios em área cultivadas com pastagens, com a neutralização do Al e/ou Mn tóxicos e aumento da disponibilidade de $\mathrm{P}$.

Os valores de acidez potencial $(\mathrm{H}+\mathrm{Al})$ não diferiram estatisticamente na profundidade $0,0-0,1 \mathrm{~m}$ (Tabela 2). Por outro lado, na profundidade de 0,1-0,2 $\mathrm{m}$ os valores de acidez potencial $(\mathrm{H}+\mathrm{Al})$ diferem entre tratamentos. Os solos cultivados com capim-Tanzânia, na presença e ausência de irrigação e com capim braquiarão em sequeiro apresentaram maiores valores absolutos de acidez potencial, quando comparados com o braquiarão irrigado.
Valores semelhantes foram encontrados por Tebaldi et al. (2000). Os solos cultivados com Tanzânia sequeiro apresentaram valores de acidez potencial estatisticamente iguais ao capim-Tanzânia irrigado e ao capim-braquiarão sequeiro, diferindo estatisticamente do braquirão irrigado, concordando com os valores encontrados por Tebaldi et al. (2000).

A capacidade de troca de cátions (CTC) apresentou o maior valor no tratamento com braquirão de sequeiro, diferindo do tratamento com capim-Tanzânia irrigado na profundidade de $0,0-0,1 \mathrm{~m}$ e resultados semelhantes foram observados na profundidade de 0,1-0,2 m. O índice de saturação por bases apresentou valores semelhantes na profundidade superficial (Tabela 2). Segundo Cruz et al. (1994), esses valores estão situados dentro da faixa de 50 a $70 \%$, indicada como ideal em áreas para implantação de pastagens.

Os maiores valores médios de matéria seca foram observados no tratamento de pastagem com braquiarão irrigado e de sequeiro, no primeiro corte, diferindo do tratamento de pastagem com Tanzânia (Tabela 3). No segundo corte, os tratamentos contendo pastagens de Tanzânia e de braquiarão irrigado e de sequeiro apresentaram resultados similares para os valores médios de matéria seca. Lopes et al. (2005), estudando o efeito da irrigação e adubação na disponibilidade e composição bromatológica de massa seca de lâminas foliares de capim-elefante, observaram que o uso da irrigação em pastagens de capim-elefante nos períodos de seca, mesmo com adubação, não foi efetivo para aumento da produção de massa seca de lâminas foliares, sobretudo para as maiores doses de adubos aplicado,

Tabela 3 - Valores médios da produção de matéria seca de capim-Tanzânia e braquiarão, sob diferentes condições de pastagens irrigadas e de sequeiro.

\begin{tabular}{lcc}
\hline \multirow{2}{*}{ Sistemas de Manejo } & Primeiro corte & Segundo Corte \\
\cline { 2 - 3 } & & $\mathrm{kg} \mathrm{MS} \mathrm{ha}^{-1}$ \\
\hline Tanzânia Irrigado & $2795,78 \mathrm{c}$ & $4646,00 \mathrm{a}$ \\
Tanzânia Sequeiro & $3120,89 \mathrm{bc}$ & $4629,11 \mathrm{a}$ \\
Braquiarão Irrigado & $4616,89 \mathrm{ab}$ & $4422,00 \mathrm{a}$ \\
Braquiarão Sequeiro & $5821,55 \mathrm{a}$ & $4887,55 \mathrm{a}$ \\
\hline DMS & 68,51 & 70,26 \\
CV $(\%)$ & 17,73 & 15,62 \\
\hline
\end{tabular}

Médias seguidas da mesma letra, na coluna, não diferem entre si pelo teste de Tukey, a $5 \%$ de probabilidade. 
onde existia a expectativa das maiores diferenças em relação às pastagens de sequeiro.

De modo geral, em gramíneas forrageiras, o fotoperíodo e a temperatura média diária, definem a produtividade ao longo do ano (PINHEIRO, 2002), mesmo com a eliminação do déficit hídrico com irrigação. A estacionalidade da produção de capimTanzânia irrigado diminui com a redução da latitude e altitude local (maior temperatura media diária). Marcelino et al. (2003), trabalhando com cv. Tifton 85 e Brachiaria brizantha, também não verificaram efeitos significativos da irrigação no período de maio a agosto, em Brasília, provavelmente, em conseqüência dos dias curtos no período, quando a temperatura mínima ficou abaixo de $17^{\circ} \mathrm{C}$.

Na profundidade de $0,0-0,2 \mathrm{~m}$, os tratamentos com Tanzânia e braquiarão de sequeiro apresentaram os maiores teores de matéria orgânica diferindo estatisticamente dos tratamentos irrigados (Tabela 4). Lima et al. (2000) verificaram teores semelhantes de matéria orgânica em Latossolo de cerrado, cultivado com Brachiaria brizantha. A irrigação pode intensificar a mineralização da matéria orgânica, embora poucos tenham avaliado esse processo. Evidências do efeito favorável da suplementação hídrica na atividade da microbiota foram obtidas por Andrén et al. (1992), os quais verificaram maior taxa de decomposição da palha de cevada, em sistema irrigado $\left(0,843 \% \mathrm{dia}^{-1}\right)$, em comparação ao não irrigado $\left(0,537 \% \mathrm{dia}^{-1}\right)$. Esses resultados indicam que condições de umidade mais favoráveis para a atividade microbiana podem refletir também, em aumento da taxa de decomposição da matéria orgânica, em solos sob irrigação.

Observaram-se maiores valores de DMG, no sistema de sequeiro com cultivo das gramíneas Tanzânia e braquiarão (2,88 e 2,69 mm, respectivamente), sendo que esses tratamentos também apresentaram os maiores valores de matéria orgânica (31,8 e 34,7 $\left.\mathrm{g} \mathrm{dm}^{-3}\right)$. Notou-se uma relação direta entre o teor de matéria orgânica do solo e o diâmetro médio geométrico nos tratamentos de sequeiro (Tabela 4), ou seja, quanto maiores os teores de matéria orgânica, maior a estabilidade de agregados. Resultados obtidos por Pinheiro et al. (2004) e Wendling et al. (2005) que relataram correlação entre a estabilidade de agregados e o teor de carbono orgânico, explicado pelo elevado poder cimentante da matéria orgânica do solo, e o acúmulo de resíduos vegetais sobre a superfície do solo.

A maior porcentagem dos agregados ficou retida na peneira de $>2,0 \mathrm{~mm}$ de malha, indicando que, em todos os tratamentos com pastagem (Tabela 4), os agregados formados são bastante estáveis em água em tamanhos maiores, concordando com resultados obtidos por Longo et al. (1999), em estudo de alterações na estabilidade de agregados em áreas sob pastagem no cerrado. Por outro lado, Alvarenga et al. (1986) afirmam que as pastagens perenes apresentam grande efeito rizosférico sobre a agregação, por apresentarem maior densidade de raízes e melhor distribuição do sistema radicular no solo, que favorecem as ligações dos pontos de contato entre as partículas minerais e os agregados.

Tabela 4 - Teor de matéria orgânica (MO), diâmetro médio geométrico (DMG) do agregado e distribuição de classes de agregados sob cultivo de pastagens irrigadas e de sequeiro, na profundidade de 0,0-0,2 m.

\begin{tabular}{|c|c|c|c|c|c|}
\hline \multirow{3}{*}{ Sistemas de Manejo } & \multirow[t]{2}{*}{ MO } & \multirow[t]{2}{*}{ DMG } & \multicolumn{3}{|c|}{ Distribuição de classes de agregados } \\
\hline & & & $>2,0 \mathrm{~mm}$ & $2,0-1,0 \mathrm{~mm}$ & $<1,0 \mathrm{~mm}$ \\
\hline & $---\mathrm{g} \mathrm{dm}^{-3}---$ & ------ mm ----- & \multicolumn{3}{|c|}{ 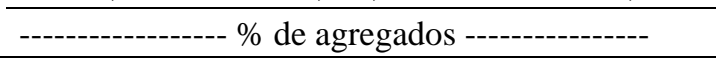 } \\
\hline Tanzânia Irrigado & $26,9 \mathrm{~b}$ & $1,39 \mathrm{~b}$ & $68,77 \mathrm{a}$ & $9,51 \mathrm{a}$ & $21,72 \mathrm{a}$ \\
\hline Tanzânia Sequeiro & $31,8 \mathrm{a}$ & $2,88 \mathrm{a}$ & $71,44 \mathrm{a}$ & $9,23 \mathrm{a}$ & 19,33 a \\
\hline Braquiarão Irrigado & $26,5 \mathrm{~b}$ & $1,69 \mathrm{~b}$ & $72,77 \mathrm{a}$ & $12,69 \mathrm{a}$ & $14,54 \mathrm{~b}$ \\
\hline Braquiarão Sequeiro & $34,7 \mathrm{a}$ & $2,69 \mathrm{a}$ & $72,70 \mathrm{a}$ & $13,28 \mathrm{a}$ & $14,02 \mathrm{~b}$ \\
\hline $\mathrm{CV}(\%)$ & 10,42 & 20,73 & 18,45 & 16,18 & 11,23 \\
\hline
\end{tabular}

Médias seguidas da mesma letra, na coluna, não diferem entre si pelo teste de Tukey, a $5 \%$ de probabilidade. 


\section{CONCLUSÕES}

Os atributos químicos variaram em ambas as profundidades, decorrentes principalmente da ação da calagem e adubação do solo independente da ausência ou presença de irrigação.

Os maiores valores do diâmetro médio geométrico (DMG) ocorreram nos sistemas de manejo que apresentam maiores teores de matéria orgânica.

A maior porcentagem dos agregados ficou retida na peneira de $>2,0 \mathrm{~mm}$ de malha, explicitando a eficiência do sistema radicular das gramíneas.

\section{REFERÊNCIAS BIBLIOGRÁFICAS}

ALVARENGA, R. C. et al. Estabilidade de agregados de um Latossolo Roxo sob diferentes métodos de preparo do solo e de manejo da palhada do milho. Revista Brasileira de Ciência do Solo, Viçosa, v. 10, n. 2, p. 273277, 1986.

ANDRÉN, O.; STEEN, E.; RAJKAI, I. Modelling the effects of moisture on barley straw and root decomposition in the field. Soil Biology $\&$ Biochemistry, Oxfort, v. 24, n. 8, p. 727-736, 1992.

BAYER, C.; MIELNICZUK, J. Características químicas do solo afetadas por métodos de preparo e sistemas de cultura. Revista Brasileira de Ciência do Solo, Viçosa, v. 21, n. 1, p. 105-112, 1997.

BODDEY, R. M. et al. Nutrient cycling and environmental impact of Brachiaria pastures. In: MILES, J. W. et al. (Eds.). Brachiaria: biology, agronomy and improvement. Cali: CIAT; Campo Grande: Embrapa-CNPGC, 1996. p. 72-86.

CARPENEDO, V.; MIELNICZUK, J. Estado de agregação e qualidade dos agregados de latossolos roxos, submetidos a diferentes sistemas de manejo. Revista Brasileira de Ciência do Solo, Viçosa, v. 14, n. 1, p. 99$105,1990$.

CARVALHO, M. M.; BOTREL, M. A.; CRUZ FILHO, A. B. Estudo exploratória de um Latossolo VermelhoAmarelo da zona dos Campos das Vertentes, MG. Revista Brasileira de Zootecnia, Viçosa, v. 21, n. 2, p. 320-328, 1992.

CARVALHO, M. M.; CRUZ FILHO, A. B.; BOTREL, M. A. Formação de pastagens. In: CURSO DE PECUÁRIA LEITURA PARA TÉCNICOS DA NESTLÉ, 3., 1984, São Paulo, SP. Anais... São Paulo: Nestlé, 1984. p. 8-81.

\section{CENTRO INTERNACIONAL DE AGRICULTURA} TROPICAL. Programa de ganado de carne. Cali: CIAT, 1988. 121 p. (Informe anual).

COMISSÃO ESTUDUAL DE FERTILIDADE DO SOLO DE GOIÁS. Recomendação de corretivos e fertilizantes para Goiás: 5a aproximação. Goiânia: UFG/Emgopa, 1988. 101 p. (Informe técnico, 1).

CRUZ, M. C. P.; FERREIRA, M. E.; LUCHETA, S. Efeito da calagem na produção de matéria seca de três gramíneas forrageiras. Pesquisa Agropecuária Brasileira, Brasília, v. 29, n. 8, p. 1303-1312, 1994.

\section{EMPRESA BRASILEIRA DE PESQUISA}

AGROPECUÁRIA. Manual de métodos de análise de solo. 2. ed. Rio de Janeiro: Ministério da Agricultura e do Abastecimento, 1997. 212 p.

\section{EMPRESA BRASILEIRA DE PESQUISA}

AGROPECUÁRIA. Centro Nacional de Pesquisa de Solos. Sistema brasileiro de classificação de solos. 2 . ed. Brasília, DF, 2006. 354 p.

EUCLIDES, V. P. B. Algumas considerações sobre manejos de pastagens. Campo Grande: Embrapa-CNPGC, 1994. 31 p. (Documentos, 57).

FAQUIN, V.; LIMA, D. V.; FURTINI NETO, A. E.; MORAES, A. R.; CURI, N.; HIGA, N. T. Nutrição mineral do braquiarão e da soja cultivados em Latossolos sob Cerrado da região de Cuiabá-MT. Ciência

Agrotecnologia, Lavras, v. 24, n. 1, p. 110-117, 2000.

KEMPER, W. D.; CHEPIL, W. S. Size distribution of aggregates. In: BLACK, C. A. (Ed.). Methods of soil analysis. Madison: American Society of Agronomy, 1965. p. 499-510.

KLEIMANN, H. J.; MAGALHÃES, R. T.; OLIVEIRA, I. P.; MORAES, M. F. Relações da produção de massa verde de Brachiaria brizantha com os índices de disponibilidade de nutrientes em solos sob massa barreirão de manejo. Pesquisa Agropecuária Tropical, Goiânia, v. 33, n. 1, p. 49-56, 2003.

KLUTHCOUSKI, J. et al. The performance of four cultivars and the effect of fertilization on beans grown under sub-irrigation in the lowland tropics. BIC, Lansing, v. 43, n. 1, p. 136-137, 2000. 
LIMA, D. V.; FAQUIN, V.; FURTINI NETO, A. E.; MORAIS, A. R.; CURI, N.; HIGA, N. T. Macro e micronutrientes no crescimento do braquiarão e da soja em Latossolo sob cerrado da região de Cuiabá-MT. Ciência e Agrotecnologia, Lavras, v. 24, n. 1, p. 96-104, 2000.

LONGO, R. M. et al. Modificações na estabilidade de agregados no solo decorrentes da introdução de pastagens em áreas de cerrado e floresta amazônica.

Revista Brasileira de Engenharia Agrícola e

Ambiental, Campina Grande, v. 3, n. 3, p. 276-280, 1999.

LOPES, R. S.; FONSECA, D. M.; OLIVEIRA, A. O. Efeito da irrigação e adubação na disponibilidade e composição bromatológica da massa seca de laminas foliares de capim elefante. Revista Brasileira de Zootecnia, Viçosa, v. 34, n. 1, p. 20-29, 2005.

LOPES, A. S.; GUILHERME, L. R. G. Solos sob cerrado: manejo da fertilidade para a produção agropecuária. São Paulo: ANDA, 1992. 49 p. (Boletim técnico, 5).

MARCELINO, K. R. A.; VILELA, L.; LEITE, G. G.; GUERRA, A. F.; DIOGO, J. M. S. Manejo da adubação nitrogenada de tensões hídricas sobre a produção de matéria seca e índice de área foliar Tfiton 85 cultivada no cerrado. Revista Brasileira de Zootecnia, Viçosa, v. 32, n. 2, p. 268-275, 2003.

MENDES, I. C.; SOUZA, L. V.; RESCK, D. V. S.; GOMES, A. C. Propriedades biológicas em agregados de um Latossolo Vermelho-Escuro sob plantio convencional e direto no cerrado. Revista Brasileira de Ciência do Solo, Viçosa, v. 27, n. 3, p. 435-443, 2003.

NASCIMENTO, J. L.; ALMEIDA, R. A.; SILVA, R. S. M.; MAGALHAES, L. A. F. Níveis de calagem e fontes de fósforo na produção do capim Tanzânia (Panicum maximum Jacq. cv. Tanzânia). Pesquisa Agropecuária Tropical, Goiânia, v. 32, n. 1, p. 7-11, 2002.
PINHEIRO, R. F. M.; PEREIRA, M. G.; ANJOS, L. H. C. Aggregates distribution and soil organic matter under different tillage systems for vegetable crops in a red Latosol from Brazil. Soil \& Tillage Research, v. 77, p. 79-84, 2004.

PINHEIRO, V. D. Variabilidade econômica da irrigação de pastagem de capim Tanzânia em diferentes regiões do Brasil. 2002. 85 f. Dissertação (Mestrado em Irrigação e Drenagem) -Universidade de São Paulo, São Paulo, 2002.

RAIJ, B. van; ANDRADE, J. C.; CANTARELLA, H. I.; QUAGGIO, J. A. (Eds.). Análise química para avaliação da fertilidade de solos tropicais. Campinas: Instituto Agronômico, 2001. 285 p.

RAIJ, B. van; ZULLO, M. A. T. Métodos de análise de solo. Campinas: Instituto Agronômico, 1977. 16 p. (Circular, 63).

SOARES, W. V.; LOBATO, E.; SOUZA, D. M. G.; REIN T. A. Avaliação do fosfato natural de gafsa para recuperação de pastagem degradada em Latossolo Vermelho-Escuro. Pesquisa Agropecuária Brasileira, Brasília, v. 35, n. 4, p. 819-825, 2000.

SOUZA, D. M. G. Correção do solo e adubação da cultura da soja. In: ARANTES, N. E.; SOUZA, P. I. M. (Eds.). Cultura da soja nos Cerrados. Piracicaba: Potafos, 1993. p. 98-101.

TEBALDI, F. L. H.; SILVA, J. F. C.; VASQUEZ, H. M.; THIEBAUT, J. T. L. Composição mineral das pastagens das regiões norte e noroeste do Estado do Rio de Janeiro: matéria orgânica, alumínio e pH dos solos. Revista Brasileira de Zootecnia, Viçosa, v. 29, n. 2, p. 382-386, 2000.

WENDLING, B.; JUCKSCH, I.; MENDONÇA, E. S.; NEVES, J. C. L. Carbono orgânico e estabilidade de agregados de um Latossolo Vermelho sob diferentes manejos. Pesquisa Agropecuária Brasileira, Brasília, v. 40, n. 5, p. 487-494, 2005. 